\title{
Under sea turtles: yellow jacks, Carangoides bartholomaei, use swimming turtles as shelter in the tropical south-western Atlantic
}

\author{
PABLO MENDONÇA ${ }^{1}$, ALICE GROSSMAN ${ }^{2}$, JOSÉ SABINO $^{3}$ AND MANUEL HAIMOVICI ${ }^{1}$ \\ ${ }^{1}$ Programa de Pós-Graduação em Oceanografia Biológica, Instituto de Oceanografia, Universidade Federal do Rio Grande, \\ Avenida Itália km 8, CP 474, 96201-90o Rio Grande, Rio Grande do Sul, Brazil, ${ }^{2}$ All Angle Images Ltda., 53990-00o, Fernando \\ de Noronha, Pernambuco, Brazil, ${ }^{3}$ Universidade Anhanguera, Laboratório de Biodiversidade, Ecologia e Conservação de \\ Ecossistemas Aquáticos-UNIDERP, CP 2153, 79003-010, Campo Grande, Mato Grosso do Sul, Brazil
}

The opportunistic carnivore fish yellow jack (Carangoides bartholomaei) is recorded using swimming hawksbill (Eretmochelys imbricata) and green (Chelonia mydas) turtles as shelter to rove at Baía do Sueste, Fernando de Noronha Archipelago, north-eastern Brazil. This behaviour is probably employed by the fish to disguise and ambush its prey while roving over the reef flat.

Keywords: 'following' behaviour, Carangidae, Cheloniidae, north-eastern Brazil

Submitted 5 January 2011; accepted 11 July 2011

\section{INTRDDUCTION}

The 'following' behaviour is a wide range association in the marine environment which involves a variety of species (Hobson, 1968; Dubin, 1982; Diamant \& Shpigel, 1985). These opportunistic strategies were described to allow individuals to benefit from an increase in foraging success or a decrease in susceptibility to predators (Strand, 1988). A total of 531 interspecific foraging associations of reef fish following nuclear species were recorded in the tropical West Atlantic at the oceanic archipelago of Fernando de Noronha, Brazil (Sazima et al., 2007). Herein we record for the first time the yellow jack Carangoides bartholomaei (Cuvier, 1833) (Carangidae), following two species of marine turtles that were not actually foraging, Chelonia mydas and Eretmochelys imbricata. The same behavioural event was recorded on nine non-consecutive occasions.

Jacks (Carangidae) are roving hunter carnivores whose opportunistic predaceous strategies include 'following' behaviour with variable foraging tactics, likely associated with a large number of nuclear species, and maybe employed according to different circumstances (Hobson, 1968). Species of Carangoides are mainly fish and crustaceans' diurnal predators (Randall, 1967). In a recent overview of nuclear-follower associations at Fernando de Noronha oceanic archipelago (Sazima et al., 2007), 13 nuclear species were recorded being followed by jacks. Besides yellow jack being recorded mainly as followers, they were also recorded in the nuclear role as well. Sometimes they were also observed being cleaned by Pomacanthus paru at the reefs of the Abrolhos Archipelago, off eastern Brazil (Sazima et al., 1999).

Corresponding author:

P. Mendonça

Email: pablomendonca@furg.br

\section{MATERIALS AND METHODS}

Field observations were made at Baía do Sueste $\left(03^{\circ} 50^{\prime} \mathrm{S}\right.$ $32^{\circ} 15^{\prime} \mathrm{W}$ ) an important area for aquatic recreation in the National Marine Park of Fernando de Noronha, where juvenile green and hawksbill sea turtles are abundant year round (Sanches \& Bellini, 1999). This bay has an inlet with an inner protected reef flat and shallow area near shore, and an outer reef slope leading to deeper parts (Sazima et al., 2010). Depths vary from 1 to $5 \mathrm{~m}$ (see Maida \& Ferreira, 1997; Sazima et al., 2004 for more details and area figure). From January to April of 2008 snorkelling dives (60-250 minutes, 41 non-consecutive dives) were conducted during studies on the natural history of sea turtles, in which all occurrences of specified behaviours were recorded during animal focal samplings (Altmann, 1974; Lehner, 1979). Behavioural events were observed directly, records pencilled on plastic slates, photographed, and occasionally videotape recorded. Straight carapace length (SCL) of turtles and total length (TL) of the fish were estimated using reference objects of known size close to the animals.

\section{RESULTS}

Most of the time solitary yellow jacks were observed roving over the reef flat normally in the mid-water and also foraging near the bottom. Both species of turtles roam over the reef area swimming close to the bottom and forage on algal turf in the central area (Chelonia mydas) or sponges near shore on the rocky outcrops (Eretmochelys imbricata). On 10 March 2008 a yellow jack of $\sim 45 \mathrm{~cm}$ TL was recorded following a swimming C. mydas of $\sim 60 \mathrm{~cm}$ SCL. During this association the fish remained close to the plastron and moved under the swimming sea turtle close to the bottom. Sometimes it left 

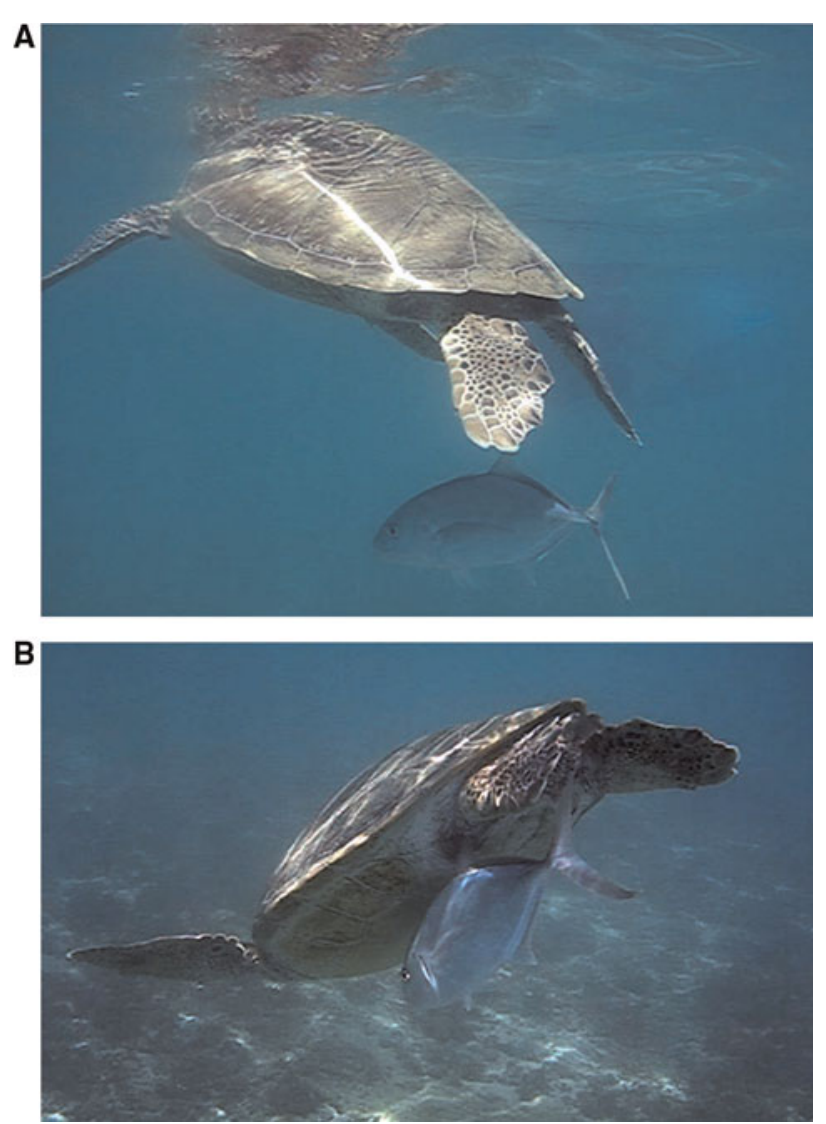

Fig. 1. A yellow jack (Carangoides bartholomaei) following a green turtle (Chelonia mydas) on the central area of a reef flat at the Baía do Sueste, Fernando de Noronha Island, off north-eastern Brazil; (A) the yellow jack remained close to the plastron while the green turtle breathed at the surface; (B) a yellow jack swimming under the same green turtle while they hovered in the mid-water. (Taken from the videotape recorded by M. Proietti.)

the 'mobile cover' trying to ambush its prey and then returned to its former position under the turtle. In two breathing events the fish followed the turtle to the surface (Figure 1). These episodes lasted 100 seconds and were video recorded. Four other similar events were also observed in the same central area of the reef flat at $2-3 \mathrm{~m}$ depth. Nevertheless, near shore at the inner and shallower area, another yellow jack of $\sim 50 \mathrm{~cm} \mathrm{TL}$ was recorded following a swimming E. imbricata of $\sim 70 \mathrm{~cm}$ (Figure 2). Three other similar events of these 'following' associations were observed at the same area close to the rocky outcrops in approximately $1 \mathrm{~m}$ depth. Overall, nine association events were pencil-recorded at depths of $1-$ $3 \mathrm{~m}$, which involved turtles of $\sim 60-70 \mathrm{~cm} \mathrm{SCL}$ and yellow jacks of $\sim 45-50 \mathrm{~cm}$ TL. The longest time recorded was approximately five minutes but associations may last longer as low water visibility $(4-5 \mathrm{~m})$ prevented further observations.

\section{DISCUSSIDN}

To the best of our knowledge this previously undescribed association is a striking departure from the usual tendency of jacks to swim higher than the attendant in the water column while as a follower (Baird, 1993; Silvano, 2001; Sazima \& Grossman, 2005; Sazima et al., 2007). These observations suggest that display can approach and exploit the disorientation of prey during hunting episodes and illustrates the behavioural flexibility of this important reef predator. The specialized ambushing behaviour was recorded for Caranx melampygus in the central Pacific (Sancho, 2000). Based on nine records involving different turtles, we suggest that this association may increase foraging opportunities for the yellow jack.

\section{ACKNOWLEDGEMENTS}

We thank Projeto TAMAR/ICMBio for logistical support; Zaira Matheus for the photographs of yellow jacks with Eretmochelys imbricata; Maíra Proietti for the video records and field support; the ICMBio for permission to study sea

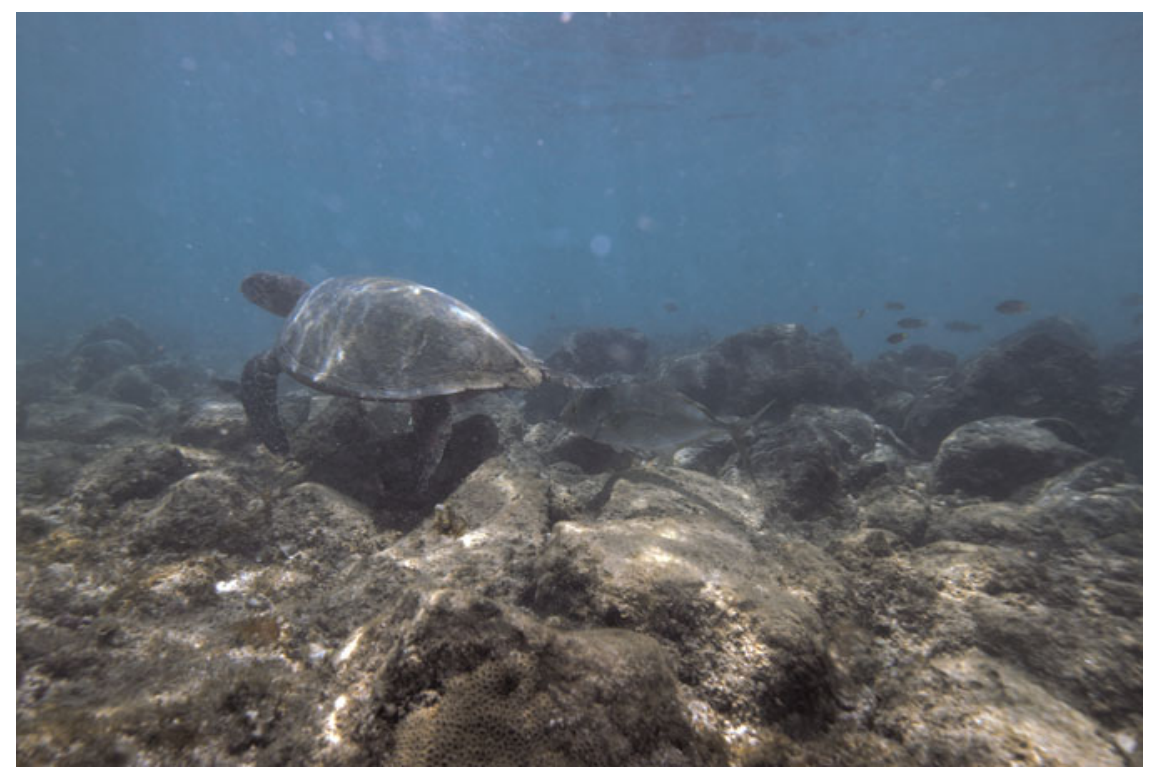

Fig. 2. A yellow jack (Carangoides bartholomaei) following a hawksbill turtle (Eretmochelys imbricata) in a shallow area near shore at the Baía do Sueste, Fernando de Noronha Island, off north-eastern Brazil. (Photograph: Zaira Matheus.) 
turtles at the National Marine Park of Fernando de Noronha. P.M. received a MS scholarship from the CNPq (National Council for Technological and Scientific DevelopmentBrazil); J.S. and M.H. received research grants from CNPq.

\section{REFERENCES}

Altmann J. (1974) Observational study of behaviour: sampling methods. Behaviour 49, 227-265.

Baird T.A. (1993) A new heterospecific foraging association between the puddingwife wrasse, Halichoeres radiatus, and the bar jack, Caranx ruber: evaluation of the foraging consequences. Environmental Biology of Fishes 38, 393-397.

Diamant A. and Shpigel M. (1985) Interspecific feeding association of groupers (Teleostei: Serranidae) with octopuses and moray eels in Gulf of Elat (Aqaba). Environmental Biology of Fishes 13, 153-159.

Dubin R.E. (1982) Behavioral interactions between Caribbean reef fish and eels (Muraenidae and Ophichthidae). Copeia 1982, 229-232.

Hobson E.S. (1968) Predatory behavior of some shore fishes in the Gulf of California. US Fish and Wildlife Service Biological Report 73, 1-92.

Lehner P.N. (1979) Handbook of ethological methods. New York: Garland STPM Press.

Maida M. and Ferreira B.P. (1997) Coral reefs of Brazil: an overview. Proceedings of the 8th International Coral Reef Symposium 1, 263-274.

Randall J.E. (1967) Food habits of reef fishes of the West Indies. Studies on Tropical Oceanography 5, 665-847.

Sanches T.M. and Bellini C. (1999) Juvenile Eretmochelys imbricata and Chelonia mydas in the Archipelago of Fernando de Noronha, Brazil. Chelonian Conservation and Biology 3, 308-311.

Sancho G. (2000) Predatory behaviors of Caranx melampygus (Carangidae) feeding on spawing reef fishes: a novel ambushing strategy. Bulletin of Marine Science 66, 487-496.
Sazima C. and Grossman A. (2005) Non-digging zoobenthivorous fish attracts two opportunistic predatory fish associates. Neotropical Ichthyology 3, 445-448.

Sazima C., Grossman A., Bellini C. and Sazima I. (2004) The moving gardens: reef fishes grazing, cleaning, and following green turtles in SW Atlantic. Cybium 28, 47-53.

Sazima C., Grossman A. and Sazima I. (2010) Turtle cleaners: reef fishes foraging on epibionts of sea turtles in the tropical Southwestern Atlantic, with a summary of this association type. Neotropical Ichthyology 8, 187-192.

Sazima C., Krajewski J.P., Bonaldo R.M. and Sazima I. (2007) Nuclear-follower foraging associations of reef fishes and other animals at an oceanic archipelago. Environmental Biology of Fishes $80,351-361$.

Sazima I., Moura R.L. and Sazima C. (1999) Cleaning activity of juvenile angelfish, Pomacanthus paru, on the reefs of the Abrolhos Archipelago, western South Atlantic. Environmental Biology of Fishes $56,399-407$.

Silvano R.A.M. (2001) Feeding habits and interspecific feeding associations of Caranx latus (Carangidae) in a subtropical reef. Environmental Biology of Fishes 60, 465-470.

and

Strand S. (1988) Following behavior: interspecific foraging associations among Gulf of California reef fishes. Copeia 1988, 351-357.

\section{Correspondence should be addressed to:}

P. Mendonça

Programa de Pós-Graduação em Oceanografia Biológica

Instituto de Oceanografia

Universidade Federal do Rio Grande

Avenida Itália $\mathrm{km} \mathrm{8,} \mathrm{CP} 474$

96201-900 Rio Grande

RS, Brazil

email: pablomendonca@furg.br 